\title{
Increased piezoelectric response in functional nanocomposites through multiwall carbon nanotube interface and fused-deposition modeling three-dimensional printing - CORRIGENDUM
}

\author{
Hoejin Kim, Fernando Torres, Md Tariqul Islam, Md Didarul Islam, Luis A. Chavez, Carlos A. Garcia Rosales, \\ Bethany R. Wilburn, Calvin M. Stewart, Juan C. Noveron, Tzu-Liang B. Tseng, and Yirong Lin
}

doi: https://doi.org/10.1557/mrc.2017.126, Published by Materials Research Society with Cambridge University Press, 8 November 2017

In Kim et al., ${ }^{1}$ a calculation error was made in the piezoelectric coefficient $d_{31}$ for 3D printed MWCNT/BT/PVDF nanocomposites. Output millivolts were used instead of volts in the equation to get the final $d_{31}$, so all values of $d_{31}$ should be divided by 1000 to get the correct values. A detailed list of corrections follows:

Abstract, line 5: the value $129 \mathrm{pC} / \mathrm{N}$ should be $0.13 \mathrm{pC} / \mathrm{N}$. The sentence beginning "Measured $d_{31}$ of $3 \mathrm{D}$ printed..." should be deleted.

Page 5, right column, paragraph 2, line 7: the values 0.22 to 57.6 $\mathrm{pC} / \mathrm{N}$ should be 0.002 to $0.058 \mathrm{pC} / \mathrm{N}$.

Page 5, right column, paragraph 2, line 13: the values $21.8(0 \mathrm{wt}$ $\%$-BT) to $129 \mathrm{pC} / \mathrm{N}(18 \mathrm{wt} \%$-BT) should be 0.022 (0 wt $\%$-BT) to $0.13 \mathrm{pC} / \mathrm{N}(18 \mathrm{wt} \%$-BT).
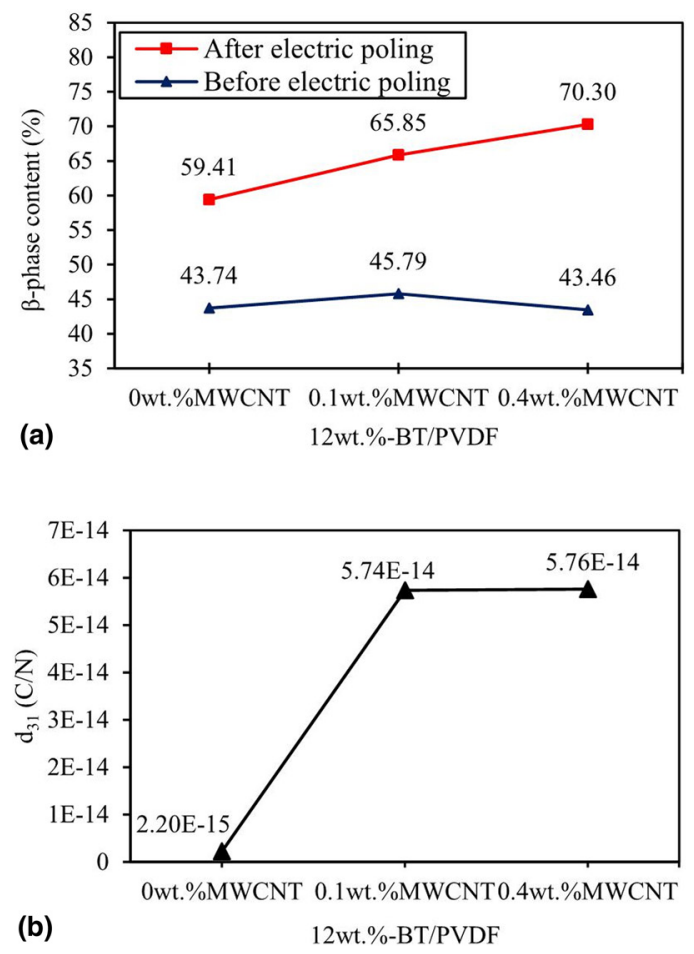

Page 5, right column, paragraph 2, line 14: the sentence beginning "The measured $d_{31}$ of the nanocomposites is comparable..." should be deleted.

Page 7, left column, paragraph 1, line 6: the value of $129 \mathrm{pC} / \mathrm{N}$ should be $0.13 \mathrm{pC} / \mathrm{N}$.

Figure 3 is corrected below.

The authors regret these errors.

\section{Reference}

1. H. Kim, F. Torres, M.T. Islam, M.D. Islam, L.A. Chavez, C.A. Garcia Rosales, B. R. Wilburn, C.M. Stewart, J.C. Noveron, T.-L.B. Tseng, and Y. Lin: Increased piezoelectric response in functional nanocomposites through multiwall carbon nanotube interface and fused-deposition modeling three-dimensional printing. MRS Communications (2017). https://doi. org/10.1557/mrc.2017.126
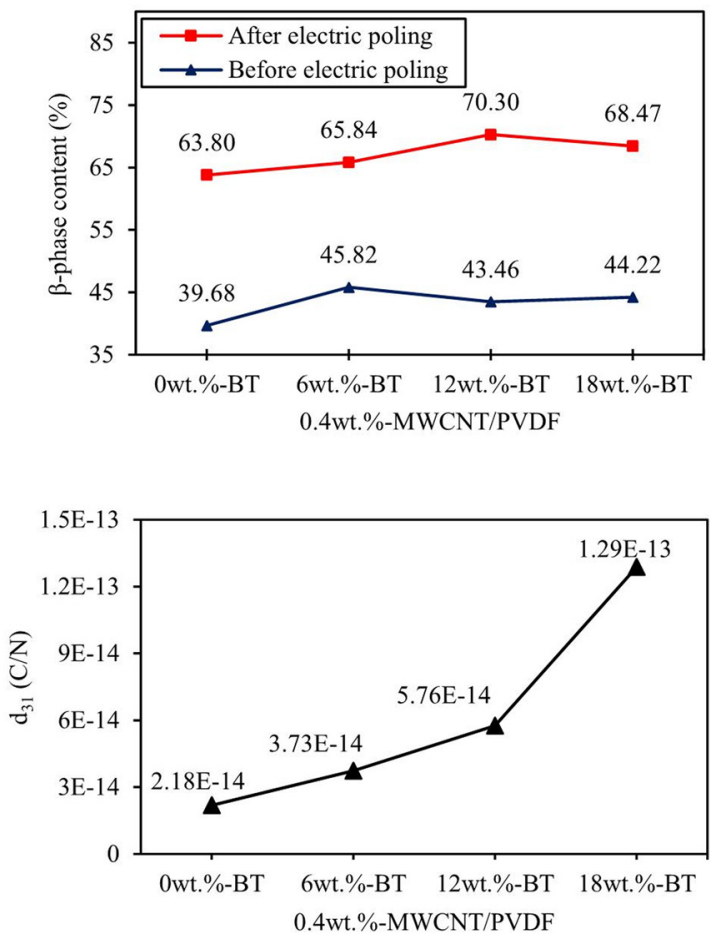